Molecular Genetics and Metabolism

2010, 100 Suppl. 1 S53-S58

\title{
Ammonia toxicity to the brain : \\ Effects on creatine metabolism and transport and protective roles of creatine
}

\section{Olivier Braissant}

\author{
Inborn Errors of Metabolism, \\ Clinical Chemistry Laboratory,
}

Centre Hospitalier Universitaire Vaudois and University of Lausanne,

CH-1011 Lausanne, Switzerland.

\section{Correspondence to: Dr. Olivier Braissant,}

Inborn Errors of Metabolism, Clinical Chemistry Laboratory,

Centre Hospitalier Universitaire Vaudois and University of Lausanne, CI 02/33, Avenue Pierre-Decker 2, CH-1011 Lausanne, Switzerland Tél : (+41.21) 314.41.52, Fax : (+41.21) 314.35.46

e-mail : Olivier.Braissant@chuv.ch 


\begin{abstract}
Hyperammonemia can provoke irreversible damage to the developing brain, with the formation of cortical atrophy, ventricular enlargement, demyelination or gray and white matter hypodensities. Among the various pathogenic mechanisms involved, alterations in cerebral energy have been demonstrated. In particular, we could show that ammonia exposure generates a secondary deficiency in creatine in brain cells, by altering the brain expression and activity of the genes allowing creatine synthesis (AGAT and GAMT) and transport (SLC6A8). On the other hand, it is known that creatine administration can exert protective effects in various neurodegenerative processes. We could also show that creatine co-treatment under ammonia exposure can protect developing brain cells from some of the deleterious effects of ammonia, in particular axonal growth impairment. This article focuses on the effects of ammonia exposure on creatine metabolism and transport in developing brain cells, and on the potential neuroprotective properties of creatine in the brain exposed to ammonium.
\end{abstract}




\section{Keywords}

Ammonia, brain, hyperammonemia, toxicity, creatine, neuroprotection

\section{Abbreviations}

AGAT: arginine:glycine amidinotransferase; BBB: blood brain barrier; CK: creatine kinase; CNS: central nervous system; Cr: creatine; GAA: guanidinoacetate; GAMT: guanidinoacetate methyltransferase; MAP-2: microtubule associated protein 2; MCEC: microcapillary endothelial cell; NFM: medium weight neurofilament protein; $\mathrm{NH}_{4}{ }^{+}$: ammonium; $\mathrm{PCr}$ : phosphocreatine; SLC6A8: creatine transporter; UCD: urea cycle disease. 


\section{1: Introduction: ammonia toxicity to the brain}

In pediatric patients, hyperammonemia can be caused by various acquired or inherited disorders such as urea cycle diseases (UCD) or organic acidemias [1]. The excess of circulating ammonia eventually reaches central nervous system (CNS), where the main toxic effects of ammonia occur. These are reversible or irreversible, depending on the age of onset as well as the duration and the level of ammonia (or more properly the ammonium ion $\mathrm{NH}_{4}{ }^{+}$) exposure. The brain is much more susceptible to the deleterious effects of $\mathrm{NH}_{4}{ }^{+}$during development than in adulthood. Hyperammonemia can provoke irreversible damage to developing CNS, with presentation symptoms such as cognitive impairment, seizures and cerebral palsy [2,3]. Hyperammonemic neonates and infants develop cortical atrophy, ventricular enlargement, demyelination or gray and white matter hypodensities [3-5]. The extent of the irreversible damage depends on the maturation of the brain and on the magnitude and duration of $\mathrm{NH}_{4}^{+}$exposure [6-8].

The last few years have brought new data showing that ammonia exposure in CNS alters several amino acid pathways and neurotransmitter systems, cerebral energy, nitric oxide synthesis, axonal and dendritic growth, signal transduction pathways, as well as $\mathrm{K}^{+}$and water channels (see this same volume of Molecular Genetics and Metabolism: [9]). All these effects of ammonia on CNS may eventually lead to energy deficit, oxidative stress and cell death.

We and others have shown that $\mathrm{NH}_{4}{ }^{+}$exposure impairs the metabolism and transport of arginine in developing brain cells [10-12]. Moreover, patients with UCD (except for deficiency in arginase I) can present shortage in arginine [13-15]. As arginine is precursor, among other pathways, of creatine $(\mathrm{Cr})$ synthesis, $\mathrm{NH}_{4}{ }^{+}$exposure of the brain can lead to 
disturbances in cerebral energy and in particular in its $\mathrm{Cr}$ content. In particular, it was shown that $\mathrm{NH}_{4}{ }^{+}$exposure generates a secondary deficiency in $\mathrm{Cr}$ in brain cells [16-18], which can be observed in vivo in UCD patients [19].

On the other hand, $\mathrm{Cr}$ administration has been postulated to exert protective effects in various neurodegenerative processes, including Huntington's and Parkinson's diseases, amyotrophic lateral sclerosis or cerebral ischemia (see discussion below) [20]. We could also show that $\mathrm{Cr}$ co-treatment under $\mathrm{NH}_{4}{ }^{+}$exposure can protect developing brain cells from some of the deleterious effects of $\mathrm{NH}_{4}{ }^{+}$, in particular axonal growth impairment [16,21].

This article will focus on the effects of $\mathrm{NH}_{4}^{+}$exposure on $\mathrm{Cr}$ metabolism and transport in developing brain cells, and on the potential neuroprotective properties of $\mathrm{Cr}$ in the brain exposed to $\mathrm{NH}_{4}^{+}$.

\section{2: Synthesis and transport of creatine in CNS}

The $\mathrm{Cr} /$ phosphocreatine $(\mathrm{PCr}) /$ creatine kinase (CK) system is essential to buffer and regenerate ATP. In mammals, $\mathrm{Cr}$ is supplied by diet, or is synthesized from arginine and glycine by a two-step mechanism involving arginine:glycine amidinotransferase (AGAT), yielding guanidinoacetate (GAA), and guanidinoacetate methyltransferase (GAMT), which converts GAA to $\mathrm{Cr}$; $\mathrm{Cr}$ is taken up by cells through a specific $\mathrm{Cr}$ transporter, SLC6A8 (also called CT1, CRT or CreaT), belonging to the $\mathrm{Na}^{+}$-dependent neurotransmitter transporter family [22-24]. In adult mammals, the main pathway for $\mathrm{Cr}$ synthesis involves AGAT in kidney, the transfer of the intermediate GAA to liver and GAMT in hepatocytes $[25,26]$. 
However, both enzymes are also expressed in various other tissues. In particular, AGAT, GAMT and SLC6A8 are expressed in the brain [27,28], which is the main affected target of patients suffering of AGAT, GAMT or SLC6A8 deficiencies, manifesting in early infancy with severe neurodevelopmental delays, autism and epileptic seizures [29].

It has long been thought that most of $\mathrm{Cr}$ in CNS was of peripheral origin. However, the mammalian brain can synthesize its own $\mathrm{Cr}[30,31]$. We and others have shown that AGAT and GAMT are expressed by all the main cellular types within the brain, namely neurons, astrocytes and oligodendrocytes [27,32-34]. This allows them to synthesize their own $\mathrm{Cr}$ $[16,18]$. The brain expression of SLC6A8 is different. In vivo, SLC6A8 is expressed by neurons and oligodendrocytes. It is also expressed by microcapillary endothelial cells (MCEC), but not by astrocytes, including in their feet lining blood brain barrier (BBB) [27,33,35-39]. This probably limits the permeability of BBB for $\mathrm{Cr}$, and made us suggest that Cr most probably does not cross BBB efficiently and that CNS depends, at least for a part of it, on its own Cr synthesis [27,24,40].

The presence of SLC6A8 in neurons and oligodendrocytes suggests the transport of $\mathrm{Cr}$ between cells synthesizing $\mathrm{Cr}$ and cells with high energy requests. We also showed recently that in the brain, AGAT and GAMT seem rarely co-expressed within the same cell, suggesting that to allow $\mathrm{Cr}$ synthesis in CNS, GAA must be transported from AGAT- to GAMT-expressing cells through SLC6A8 $[28,41]$.

AGAT, GAMT and SLC6A8 are also well expressed during vertebrate embryogenesis $[42,43]$, and probably play essential roles in developing CNS as their deficiencies lead to neurological symptoms and severe neurodevelopmental delay in early infancy [29]. 


\section{3: Functions of creatine in CNS}

The main function of the $\mathrm{Cr} / \mathrm{PCr} / \mathrm{CK}$ system in vertebrate cells is the regeneration of ATP as well as the cell buffering of high energy phosphates [22-24]. In CNS specifically, the importance of $\mathrm{Cr}$ has been shown for the dendritic and axonal elongation (growth cone migration), the $\mathrm{Na}^{+}-\mathrm{K}^{+}$-ATPase activity, the release of various neurotransmitters, the maintenance of membrane potential, the $\mathrm{Ca}^{++}$homeostasis and the restoration of ion gradients.

In the mammalian brain, total levels of $\mathrm{Cr}$ and $\mathrm{CK}$ activity are well correlated, their highest levels being reached in brain cells described with high and fluctuating energy demands, where AGAT, GAMT and SLC6A8 are expressed [22,40,44-46].

Beside its functions in buffering and transport of high energy phosphates, new roles for $\mathrm{Cr}$ have recently been suggested in CNS. Cr and GAA can affect GABA-ergic neurotransmission as partial agonists on post-synaptic $\operatorname{GABA}(\mathrm{A})$ receptors [47-50]. These data stimulated research showing that $\mathrm{Cr}$ is exocytotically released from central neurons in an action potential-dependent manner [51], and may thus be considered as neuromodulator or even true neurotransmitter. $\mathrm{Cr}$ was also suggested as an essential brain cell osmolyte, particularly in astrocytes which, when exposed to hypo-osmotic swelling conditions, stimulate the release of their osmotically active $\mathrm{Cr}[52,53]$. In contrast, ammonium-exposed MCEC in vitro stimulate their Cr uptake [54], suggesting that cells composing BBB (e.g. MCEC and astrocytes lining them) behave differentially during swelling. Finally, Cr was proposed to regulate appetite and weight by acting on specific hypothalamic nuclei [55]. 


\section{4: Brain cell 3D cultures: a model for analyzing the effects of $\mathrm{NH}_{4}{ }^{+}$on $\mathrm{CNS}$}

We have developed primary brain cell $3 \mathrm{D}$ cultures in aggregates as a valid experimental model to study the effects of $\mathrm{NH}_{4}{ }^{+}$on developing CNS $[10,16,18,56]$. These cultures are prepared from the CNS of rat embryos, contain all types of brain cells (neurons, astrocytes, oligodendrocytes, microglia) and consist of even-sized spheres that are maintained in suspension by constant gyratory agitation in a serum-free, Cr-free, chemically-defined medium. They are classified as organotypic as their different cell types interact together and develop specialized structures (synapses, myelinated axons) as well as electrical activity in a manner resembling in vivo CNS [56]. Hyperammonemia is mimicked in this model by treating cultures with $\mathrm{NH}_{4} \mathrm{Cl}$ [16]. Compared to classical monotypic cultures, 3D brain cell cultures present the advantage to allow the study of irreversible $\mathrm{NH}_{4}{ }^{+}$toxicity in a model that mimic brain complexity at different stages of maturation. At the same time, these cultures allow to study the effects of hyperammonemia devoid of the confusing variables attributable to secondary effects of hyperammonemia found in animal models [57]. Brain cell 3D cultures

synthesize their own $\mathrm{Cr}$ and express AGAT, GAMT and SLC6A8 as the in vivo CNS, showing in particular the absence of SLC6A8 in astrocytes under normal conditions $[16,18]$.

\section{5: $\mathrm{NH}_{4}{ }^{+}$impairs axonal growth and generates a secondary $\mathrm{Cr}$ deficiency in brain cells}


The developing brain of hyperammonemic neonates and infants can present cortical atrophy or gray and white matter hypodensities, which are reminiscent of neuronal fiber loss or defects of neurite outgrowth. A loss of medium spiny neurons and increased numbers of reactive oligodendroglia and microglia in striatum are also observed [58]. Spf mice show a decrease in both dendritic tree complexity and spine density in the layer V pyramidal cells of frontoparietal cortex [59]. Alteration of neurite outgrowth by hyperammonemia might be due to dysregulation of cytoskeletal elements. $\mathrm{NH}_{4}{ }^{+}$-acetate fed rats present a decreased phosphorylation of the dendritic protein microtubule associated protein 2 (MAP-2), in parallel with an increase of MAP-2 binding to microtubules [60]. We showed that $\mathrm{NH}_{4}{ }^{+}$exposure in 3D brain cell cultures inhibits axonal growth, together with a decreased medium weight neurofilament (NFM) expression and phosphorylation (Figure 1; $[16,61]$ ). This occurs only in developing brain cells but not after neuronal maturation and synaptogenesis (Figure 1), in line with clinical data showing $\mathrm{NH}_{4}{ }^{+}$-induced irreversible damage to $\mathrm{CNS}$ in neonates and infants but not in adults [62].

As, during CNS development, $\mathrm{Cr}$ is particularly important during neurite elongation at the levels of growth cones, we hypothesized that developing brain cells under $\mathrm{NH}_{4}{ }^{+}$exposure may undergo a decrease in their Cr pools.

We could thus show that axonal growth inhibition by $\mathrm{NH}_{4}{ }^{+}$during brain cell development is indeed accompanied by a decrease of intracellular $\mathrm{Cr}$ in developing brain cells (Figure 2; $[16,18])$. To better understand how $\mathrm{NH}_{4}{ }^{+}$alters $\mathrm{Cr}$ pools in CNS, we analyzed AGAT, GAMT and SLC6A8 gene regulation in 3D brain cell cultures under $\mathrm{NH}_{4}{ }^{+}$exposure [18], and measured intracellular levels of $\mathrm{Cr}$ and GAA by tandem mass spectroscopy. We showed that the $\mathrm{Cr} / \mathrm{GAA}$ ratio in $\mathrm{NH}_{4}{ }^{+}$-exposed brain cells was increased, suggesting an inhibition of 
AGAT enzymatic activity under $\mathrm{NH}_{4}{ }^{+}$exposure (Table 1). $\mathrm{NH}_{4}{ }^{+}$exposure also differentially altered AGAT, GAMT and SLC6A8 gene expression and protein activity, in a cell typespecific manner. In particular, we found that $\mathrm{NH}_{4}{ }^{+}$exposure induces SLC6A8 expression in astrocytes, while it represses it in oligodendrocytes (Table 1). We also showed that it increased GAMT expression in oligodendrocytes [18]. This probably alters the energy requirements of these respective glial cells. This might be related to the increased number of astrocytic mitochondria observed under hyperammonemia, in parallel with astrocyte swelling and Alzheimer's type II astrocytosis, while in contrast the number of oligodendrocytic mitochondria is decreased [63-65].

\section{6: Neuroprotection by creatine under $\mathrm{NH}_{4}{ }^{+}$exposure}

As $\mathrm{NH}_{4}^{+}$exposure inhibits axonal growth and generates a simultaneous secondary $\mathrm{Cr}$ deficiency in brain cells, the next experimental step was to investigate whether a Cr cotreatment under $\mathrm{NH}_{4}{ }^{+}$exposure could be neuroprotective, in particular on axonal growth. Indeed, we could show that a Cr co-treatment is able to protect axonal growth under $\mathrm{NH}_{4}{ }^{+}$ exposure (Figure 3 A-C; [16]). However, this was possible only in the presence of glial cells. When neuron-enriched 3D cultures were used, in which glial cells have been wiped out by cytosine arabinoside, axonal growth was still impaired by $\mathrm{NH}_{4}{ }^{+}$exposure, but $\mathrm{Cr}$ co-treatment did not exert any protection on axonal growth (Figure 3 D-F; [16]). Thus, the mechanism of axonal protection by $\mathrm{Cr}$ is glial cell-dependent. This protecting factor, be it glial or neuronal under glial dependence, is stimulated by $\mathrm{Cr}$ treatment and can be a contact or a soluble factor. To solve this, mixed-cell 3D cultures (i.e: containing glial cells) were treated with $1 \mathrm{mM} \mathrm{Cr}$, and their culture medium was used to condition neuron-enriched aggregates exposed to $5 \mathrm{mM}$ 
$\mathrm{NH}_{4} \mathrm{Cl}$. These conditions allowed the protection of axonal growth in neuron-enriched cultures exposed to $\mathrm{NH}_{4}{ }^{+}$(Figure 3 G). Thus, a soluble, glial-dependent factor appears implicated in the axonal growth protection by $\mathrm{Cr}$ under $\mathrm{NH}_{4}^{+}$exposure.

As $\mathrm{NH}_{4}{ }^{+}$exposure inhibits axonal growth and decreases $\mathrm{Cr}$, while $\mathrm{Cr}$ co-treatment under $\mathrm{NH}_{4}{ }^{+}$protects axonal growth [16], methods to efficiently sustain $\mathrm{Cr}$ concentration in the developing hyperammonemic CNS should be assessed. Under physiological conditions, $\mathrm{Cr}$ can cross from blood to brain through BBB [35], but with a low permeability [66], partly because astrocytes lining BBB do not express SLC6A8 $[18,27,28]$. This explains why AGATand GAMT-deficient patients, who can benefit from Cr supplementation, have to be treated on months with very high doses of $\mathrm{Cr}$ to replenish their cerebral $\mathrm{Cr}[29,67]$. MCEC at BBB express SLC6A8 [35]. $\mathrm{NH}_{4}{ }^{+}$exposure increases both SLC6A8 and $\mathrm{Cr}$ uptake in MCEC [54]. As we demonstrate that SLC6A8 is induced in $\mathrm{NH}_{4}{ }^{+}$-exposed astrocytes, $\mathrm{BBB}$ of the hyperammonemic CNS might thus be more permeable to $\mathrm{Cr}$ than under physiological conditions, and supplying oral $\mathrm{Cr}$ to hyperammonemic neonates or infants might likely contribute to protect their brain development. The question of treating hyperammonemic patients with $\mathrm{Cr}$ should be put in perspective of the treatment of other brain pathologies with Cr. Indeed, $\mathrm{Cr}$ administration can exert protective effects in various neurodegenerative processes, including Huntington's and Parkinson's diseases [20], for which phase II (Huntington's and Parkinson's diseases) and phase III (Huntington's) clinical trials are already ongoing $[68,69]$.

\section{7: Dependence on the brain cell model: discrepancies on Cr metabolism and}

\section{transport}


As described above, it has been known for a long time that CNS can synthesize Cr [31], however until recently almost nothing was known, at the molecular level, on the way brain cells synthesize and / or take up Cr. 20 years ago, an important paper by Möller and Hamprecht showed a detailed description of the capacity of $\mathrm{Cr}$ uptake in vitro by numerous types of primary brain cells as well as immortalized cell lines [70]. They concluded that astrocytes have the highest activity of $\mathrm{Cr}$ transporter.

We showed that in vivo AGAT and GAMT can be found in all cell types of the brain, while, in contrast to what was demonstrated in primary cultures of astrocytes, SLC6A8 is not expressed in astrocytes [27]. We further demonstrated that organotypic cultures like brain 3D mixed-cell cultures synthesize their own $\mathrm{Cr}$ and express AGAT, GAMT and SLC6A8 as the in vivo CNS, including the absence of SLC6A8 from astrocytes [18].

In contrast, when we analyzed brain 3D neuron-enriched cultures, from which astrocytes and oligodendrocytes have been eliminated, we showed that in absence of glial cells, AGAT and GAMT are totally silent from neurons and from the very few remaining astrocytes, while both genes are well expressed in both cell types when glial cells are present [18]. This is also reflected by the intracellular $\mathrm{Cr}$ of neuron-enriched cultures, which is measured at levels 10 times lower than in mixed-cell cultures.

It appears thus that monotypic primary brain cells, be them in monolayers or in $3 \mathrm{D}$ cultures, do not behave as the in vivo CNS for $\mathrm{Cr}$ metabolism and transport. Thus, to analyze $\mathrm{Cr}$ in brain cells in conditions as near as possible of the in vivo brain, complex 3D, organotypic and mixed-cell culture systems should be used. 


\section{8: Conclusions}

Hyperammonemia during development is associated with neuronal cell loss and cerebral atrophy that lead to mental retardation and cerebral palsy in pediatric patients. Among the various pathogenic mechanisms involved, alterations in axonal and dendritic growth and cerebral energy have been demonstrated.

As illustrated in this article, $\mathrm{NH}_{4}{ }^{+}$exposure impairs axonal growth in developing brain cells and simultaneously generates a secondary Cr deficiency, likely through inhibition of AGAT activity. A Cr co-treatment can protect axonal growth under $\mathrm{NH}_{4}{ }^{+}$exposure, in dependency of glial cells.

Finally, the Cr transporter, SLC6A8, which is normally silent in astrocytes in vivo, is induced in astrocytes by $\mathrm{NH}_{4}{ }^{+}$exposure, which also increases SLC6A8 expression and $\mathrm{Cr}$ uptake in MCEC. This might facilitate the entry of $\mathrm{Cr}$ into the brain, and raises the question of the potential treatment of hyperammonemic patient with $\mathrm{Cr}$ to protect their developing CNS. 


\section{Acknowledgments}

This work was supported by the Swiss National Science Foundation, grants $n^{\circ} 3100 A 0-$ 100778 and $3100 \mathrm{~A} 0-116859$.

\section{References}

[1] L. Cagnon, O. Braissant, Hyperammonemia-induced toxicity for the developing central nervous system, Brain Res. Rev. 56 (2007) 183-197.

[2] M. Flint Beal, J.B. Martin. Major complications of cirrhosis, in: A.S. Fauci, E. Braunwald, K.J. Isselbacher, J.D. Wilson, J.B. Martin, D.L. Kasper, S.L. Hauser, D.L. Longo (Eds.), Harrison's principles of internal medicine, McGraw-Hill, New-York, 1998, pp. 2451-2457.

[3] G.M. Enns, Neurologic damage and neurocognitive dysfunction in urea cycle disorders, Semin. Pediatr. Neurol. 15 (2008) 132-139.

[4] M. Tuchman, B. Lee, U. Lichter-Konecki, M.L. Summar, M. Yudkoff, S.D. Cederbaum, D.S. Kerr, G.A. Diaz, M.R. Seashore, H.S. Lee, R.J. McCarter, J.P. Krischer, M.L. Batshaw, Cross-sectional multicenter study of patients with urea cycle disorders in the United States, Mol. Genet. Metab. 94 (2008) 397-402.

[5] A.L. Gropman, M. Summar, J.V. Leonard, Neurological implications of urea cycle disorders, J. Inherit. Metab. Dis. 30 (2007) 865-879. 
[6] G.M. Enns, S.A. Berry, G.T. Berry, W.J. Rhead, S.W. Brusilow, A. Hamosh, Survival after treatment with phenylacetate and benzoate for urea-cycle disorders, N. Engl. J. Med. 356 (2007) 2282-2292.

[7] C. Bachmann, Mechanisms of hyperammonemia, Clin. Chem. Lab. Med. 40 (2002) 653-662.

[8] C. Bachmann, Outcome and survival of 88 patients with urea cycle disorders: a retrospective evaluation, Eur. J. Pediatr. 162 (2003) 410-416.

[9] O. Braissant, Current concepts in the pathogenesis of urea cycle disorders, Mol. Gen. Metab. (2010).

[10] O. Braissant, P. Honegger, M. Loup, K. Iwase, M. Takiguchi, C. Bachmann, Hyperammonemia: regulation of argininosuccinate synthetase and argininosuccinate lyase genes in aggregating cell cultures of fetal rat brain, Neurosci. Lett. 266 (1999) $89-92$

[11] C. Bachmann, O. Braissant, A.M. Villard, O. Boulat, H. Henry, Ammonia toxicity to the brain and creatine, Mol. Genet. Metab. 81 Suppl 1 (2004) S52-S57.

[12] V.L.R. Rao, Nitric oxide in hepatic encephalopathy and hyperammonemia, Neurochem. Int. 41 (2002) 161-170.

[13] F. Scaglia, N. Brunetti-Pierri, S. Kleppe, J. Marini, S. Carter, P. Garlick, F. Jahoor, W. O'Brien, B. Lee, Clinical consequences of urea cycle enzyme deficiencies and potential links to arginine and nitric oxide metabolism, J. Nutr. 134 (2004) 2775S2782S. 
[14] F. Scaglia, B. Lee, Clinical, biochemical, and molecular spectrum of hyperargininemia due to arginase I deficiency, Am. J. Med. Genet. C. Semin. Med. Genet. 142 (2006) 113-120.

[15] J.V. Leonard, A.A. Morris, Urea cycle disorders, Semin. Neonatol. 7 (2002) 27-35.

[16] O. Braissant, H. Henry, A.M. Villard, M.G. Zurich, M. Loup, B. Eilers, G. Parlascino, E. Matter, O. Boulat, P. Honegger, C. Bachmann, Ammonium-induced impairment of axonal growth is prevented through glial creatine, J. Neurosci. 22 (2002) 9810-9820.

[17] O. Braissant, Pathways depending on urea cycle intermediates, in: C. Bachmann, J. Häberle, H.G. Koch, J. Leonard (Eds.), Pathophysiology and Management of Hyperammonemia, SPS Publications, Heilbronn, 2007, pp. 25-41.

[18] O. Braissant, L. Cagnon, F. Monnet-Tschudi, O. Speer, T. Wallimann, P. Honegger, H. Henry, Ammonium alters creatine transport and synthesis in a 3D-culture of developing brain cells, resulting in secondary cerebral creatine deficiency, Eur. J. Neurosci. 27 (2008) 1673-1685.

[19] C.G. Choi, H.W. Yoo, Localized proton MR spectroscopy in infants with urea cycle defect, AJNR Am. J. Neuroradiol. 22 (2001) 834-837.

[20] A.M. Klein, R.J. Ferrante, The neuroprotective role of creatine, Subcell. Biochem. 46 (2007) 205-243.

[21] O. Braissant, H. Henry, L. Cagnon, P. Honegger, C. Bachmann, Glial mechanisms of axonal growth protection from ammonia, in: D. Häussinger, G. Kircheis, F. Schliess (Eds.), Hepatic encephalopathy and nitrogen metabolism, Springer, Dordrecht, Berlin, Heidelberg, New York, 2006, pp. 124-133. 
[22] M. Wyss, R. Kaddurah-Daouk, Creatine and creatinine metabolism, Physiol. Rev. 80 (2000) 1107-1213.

[23] J.T. Brosnan, M.E. Brosnan, Creatine: endogenous metabolite, dietary, and therapeutic supplement, Annu. Rev. Nutr. 27 (2007) 241-261.

[24] T. Wallimann, M. Tokarska-Schlattner, D. Neumann, R.M. Epand, R.F. Epand, R.H. Andres, H.R. Widmer, T. Hornemann, V.A. Saks, I. Agarkova, U. Schlattner, The phosphocreatine circuit: Molecular and cellular physiology of creatine kinases, sensitivity to free radicals and enhancement of creatine supplementation, in: V.A. Saks (Ed.), Molecular systems bioenergetics: Energy for life, basic principles, organization and dynamics of cellular energetics, Wiley VCH-Publisher Co., Weinheim, 2007, pp. 195-264.

[25] E.E. Edison, M.E. Brosnan, C. Meyer, J.T. Brosnan, Creatine synthesis: production of guanidinoacetate by the rat and human kidney in vivo, Am. J. Physiol. Renal. Physiol. 293 (2007) F1799-F1804.

[26] R.P. da Silva, I. Nissim, M.E. Brosnan, J.T. Brosnan, Creatine synthesis: hepatic metabolism of guanidinoacetate and creatine in the rat in vitro and in vivo, Am. J. Physiol. Endocrinol. Metab. 296 (2009) E256-E261.

[27] O. Braissant, H. Henry, M. Loup, B. Eilers, C. Bachmann, Endogenous synthesis and transport of creatine in the rat brain: an in situ hybridization study, Mol. Brain Res. 86 (2001) 193-201.

[28] O. Braissant, H. Henry, AGAT, GAMT and SLC6A8 distribution in the central nervous system, in relation to creatine deficiency syndromes: A review, J. Inher. Metab. Dis. 31 (2008) 230-239. 
[29] S. Stöckler, P.W. Schutz, G.S. Salomons, Cerebral creatine deficiency syndromes: Clinical aspects, treatment and pathophysiology, Subcell. Biochem. 46 (2007) 149166.

[30] J.F. Van Pilsum, G.C. Stephens, D. Taylor, Distribution of creatine, guanidinoacetate and enzymes for their biosynthesis in the animal kingdom. Implications for phylogeny, Biochem. J. 126 (1972) 325-345.

[31] J.J. Pisano, D. Abraham, S. Udenfriend, Biosynthesis and disposition of $\gamma$ guanidinobutyric acid in mammalian tissues, Arch. Biochem. Biophys. 100 (1963) 323-329.

[32] A. Schmidt, B. Marescau, E.A. Boehm, W.K. Renema, R. Peco, A. Das, R. Steinfeld, S. Chan, J. Wallis, M. Davidoff, K. Ullrich, R. Waldschutz, A. Heerschap, P.P. De Deyn, S. Neubauer, D. Isbrandt, Severely altered guanidino compound levels, disturbed body weight homeostasis and impaired fertility in a mouse model of guanidinoacetate N-methyltransferase (GAMT) deficiency, Hum. Mol. Genet. 13 (2004) 905-921.

[33] M. Tachikawa, M. Fukaya, T. Terasaki, S. Ohtsuki, M. Watanabe, Distinct cellular expressions of creatine synthetic enzyme GAMT and creatine kinases uCK-Mi and CK-B suggest a novel neuron-glial relationship for brain energy homeostasis, Eur. J. Neurosci. 20 (2004) 144-160.

[34] T. Nakashima, M. Tomi, M. Tachikawa, M. Watanabe, T. Terasaki, K. Hosoya, Evidence for creatine biosynthesis in Müller glia, Glia 52 (2005) 47-52. 
[35] S. Ohtsuki, M. Tachikawa, H. Takanaga, H. Shimizu, M. Watanabe, K. Hosoya, T. Terasaki, The blood-brain barrier creatine transporter is a major pathway for supplying creatine to the brain, J. Cereb. Blood Flow Metab. 22 (2002) 1327-1335.

[36] T. Nakashima, M. Tomi, K. Katayama, M. Tachikawa, M. Watanabe, T. Terasaki, K. Hosoya, Blood-to-retina transport of creatine via creatine transporter (CRT) at the rat inner blood-retinal barrier, J. Neurochem. 89 (2004) 1454-1461.

[37] M.L. Acosta, M. Kalloniatis, D.L. Christie, Creatine transporter localization in developing and adult retina: importance of creatine to retinal function, Am. J. Physiol. Cell Physiol. 289 (2005) C1015-C1023.

[38] M. Tachikawa, J. Fujinawa, M. Takahashi, Y. Kasai, M. Fukaya, K. Sakai, M. Yamazaki, M. Tomi, M. Watanabe, K. Sakimura, T. Terasaki, K. Hosoya, Expression and possible role of creatine transporter in the brain and at the blood-cerebrospinal fluid barrier as a transporting protein of guanidinoacetate, an endogenous convulsant, J. Neurochem. 107 (2008) 768-778.

[39] C.S. Mak, H.J. Waldvogel, J.R. Dodd, R.T. Gilbert, M.T. Lowe, N.P. Birch, R.L. Faull, D.L. Christie, Immunohistochemical localisation of the creatine transporter in the rat brain, Neuroscience 163 (2009) 571-585.

[40] O. Braissant, C. Bachmann, H. Henry, Expression and function of AGAT, GAMT and CT1 in the mammalian brain, Subcell. Biochem. 46 (2007) 67-81.

[41] O. Braissant, E. Béard, C. Torrent, H. Henry, Dissociation of AGAT, GAMT and SLC6A8 in CNS: relevance to creatine deficiency syndromes, Neurobiol. Dis. in press (2010). 
[42] O. Braissant, H. Henry, A.M. Villard, O. Speer, T. Wallimann, C. Bachmann, Creatine synthesis and transport during rat embryogenesis: spatiotemporal expression of AGAT, GAMT and CT1, BMC Dev. Biol. 5 (2005) 9.

[43] L. Wang, Y. Zhang, M. Shao, H. Zhang, Spatiotemporal expression of the creatine metabolism related genes agat, gamt and ct1 during zebrafish embryogenesis, Int. J. Dev. Biol. 51 (2007) 247-253.

[44] D. Holtzman, E. McFarland, T. Moerland, J. Koutcher, M.J. Kushmerick, L.J. Neuringer, Brain creatine phosphate and creatine kinase in mice fed an analogue of creatine, Brain Res. 483 (1989) 68-77.

[45] W. Hemmer, E. Zanolla, E.M. Furter-Graves, H.M. Eppenberger, T. Wallimann, Creatine kinase isoenzymes in chicken cerebellum: specific localization of brain-type creatine kinase in Bergmann glial cells and muscle-type creatine kinase in Purkinje neurons, Eur. J. Neurosci. 6 (1994) 538-549.

[46] Y. Wang, S.J. Li, Differentiation of metabolic concentrations between gray matter and white matter of human brain by in vivo ${ }^{1} \mathrm{H}$ magnetic resonance spectroscopy, Magn. Reson. Med. 39 (1998) 28-33.

[47] P.P. De Deyn, B. Marescau, R.L. Macdonald, Guanidino compounds that are increased in hyperargininemia inhibit GABA and glycine responses on mouse neurons in cell culture, Epilepsy Res. 8 (1991) 134-141.

[48] A. Neu, H. Neuhoff, G. Trube, S. Fehr, K. Ullrich, J. Roeper, D. Isbrandt, Activation of GABA(A) receptors by guanidinoacetate: a novel pathophysiological mechanism, Neurobiol. Dis. 11 (2002) 298-307. 
[49] P.P. De Deyn, R. D'Hooge, P.P. Van Bogaert, B. Marescau, Endogenous guanidino compounds as uremic neurotoxins, Kidney Int. Suppl 78 (2001) S77-S83.

[50] A. Cupello, M. Balestrino, E. Gatta, F. Pellistri, S. Siano, M. Robello, Activation of cerebellar granule cells GABA(A) receptors by guanidinoacetate, Neuroscience 152 (2008) 65-69.

[51] L.S. Almeida, G.S. Salomons, F. Hogenboom, C. Jakobs, A.N. Schoffelmeer, Exocytotic release of creatine in rat brain, Synapse 60 (2006) 118-123.

[52] J.H. Bothwell, C. Rae, R.M. Dixon, P. Styles, K.K. Bhakoo, Hypo-osmotic swellingactivated release of organic osmolytes in brain slices: implications for brain oedema in vivo, J. Neurochem. 77 (2001) 1632-1640.

[53] J.H. Bothwell, P. Styles, K.K. Bhakoo, Swelling-activated taurine and creatine effluxes from rat cortical astrocytes are pharmacologically distinct, J. Membr. Biol. 185 (2002) 157-164.

[54] M. Bélanger, T. Asashima, S. Ohtsuki, H. Yamaguchi, S. Ito, T. Terasaki, Hyperammonemia induces transport of taurine and creatine and suppresses claudin-12 gene expression in brain capillary endothelial cells in vitro, Neurochem. Int. 50 (2007) 95-101.

[55] R.A. Galbraith, M. Furukawa, M. Li, Possible role of creatine concentrations in the brain in regulating appetite and weight, Brain Res. 1101 (2006) 85-91.

[56] P. Honegger, F. Monnet-Tschudi, Aggregating neural cell culture, in: S. Fedoroff, A. Richardson (Eds.), Protocols for neural cell culture, Humana Press Inc., Totowa NJ, 2001, pp. 199-218. 
[57] C. Bachmann, Ornithine carbamoyl transferase deficiency: findings, models and problems, J. Inherit. Metab. Dis. 15 (1992) 578-591.

[58] M.B. Robinson, K. Hopkins, M.L. Batshaw, B.A. McLaughlin, M.P. Heyes, M.L. Oster-Granite, Evidence of excitotoxicity in the brain of the ornithine carbamoyltransferase deficient sparse fur mouse, Brain Res. Dev. Brain Res. 90 (1995) 35-44.

[59] K.J. Hopkins, J. McKean, R.F. Mervis, M.L. Oster-Granite, Dendritic alterations in cortical pyramidal cells in the sparse fur mouse, Brain Res. 797 (1998) 167-172.

[60] V. Felipo, E. Grau, M.D. Minana, S. Grisolia, Activation of NMDA receptor mediates the toxicity of ammonia and the effects of ammonia on the microtubule-associated protein MAP-2, Adv. Exp. Med. Biol. 341 (1993) 83-93.

[61] O. Braissant, Neurofilament proteins in brain diseases, in: R.K. Arlen (Ed.), New Research on Neurofilament Proteins, Nova Science Publishers Inc., New York, 2006, pp. $25-51$.

[62] S.W. Brusilow, A.L. Horwich, Urea cycles enzymes, in: C.R. Scriver, A.L. Beaudet, W.S. Sly, D. Valle (Eds.), The metabolic and molecular bases of inherited disease. McGraw-Hill, New York, 2001, pp. 1909-1963.

[63] H. Laursen, N.H. Diemer, Morphometry of astrocyte and oligodendrocyte ultrastructure after portocaval anastomosis in the rat, Acta Neuropathol. 51 (1980) 6570.

[64] R.F. Butterworth, Effects of hyperammonaemia on brain function, J. Inher. Metab. Dis. 21 Suppl 1 (1998) 6-20. 
[65] M.D. Norenberg, K.V. Rao, A.R. Jayakumar, Mechanisms of ammonia-induced astrocyte swelling, Metab. Brain. Dis. 20 (2005) 303-318.

[66] L. Perasso, A. Cupello, G.L. Lunardi, C. Principato, C. Gandolfo, M. Balestrino, Kinetics of creatine in blood and brain after intraperitoneal injection in the rat, Brain Res. 974 (2003) 37-42.

[67] A. Schulze, R. Battini, Pre-symptomatic treatment of creatine biosynthesis defects, Subcell. Biochem. 46 (2007) 167-181.

[68] A. Bender, W. Koch, M. Elstner, Y. Schombacher, J. Bender, M. Moeschl, F. Gekeler, B. Müller-Myhsok, T. Gasser, K. Tatsch, T. Klopstock, Creatine supplementation in Parkinson disease: a placebo-controlled randomized pilot trial, Neurology 67 (2006) $1262-1264$.

[69] S.M. Hersch, S. Gevorkian, K. Marder, C. Moskowitz, A. Feigin, M. Cox, P. Como, C. Zimmerman, M. Lin, L. Zhang, A.M. Ulug, M.F. Beal, W. Matson, M. Bogdanov, E. Ebbel, A. Zaleta, Y. Kaneko, B. Jenkins, N. Hevelone, H. Zhang, H. Yu, D. Schoenfeld, R. Ferrante, H.D. Rosas, Creatine in Huntington disease is safe, tolerable, bioavailable in brain and reduces serum $8 \mathrm{OH} 2$ 'dG, Neurology 66 (2006) 250-252.

[70] A. Möller, B. Hamprecht, Creatine transport in cultured cells of rat and mouse brain, J. Neurochem. 52 (1989) 544-550. 
Table 1 : Main effects of $\mathrm{NH}_{4}{ }^{+}$on AGAT, GAMT and SLC6A8 expression and activity in brain cells (data taken, and figure modified, from [18]) ${ }^{a}$.

\begin{tabular}{|lc|c|}
\hline Effects of $\mathbf{N H}_{\mathbf{4}}{ }^{+}$on: & & in (cells involved) : \\
\hline AGAT activity : & $\Downarrow$ & ND \\
\hline GAMT expression : & $\Uparrow$ & oligodendrocytes \\
\hline SLC6A8 expression : & $\Uparrow$ & astrocytes \\
& $\Downarrow$ & oligodendrocytes \\
\hline
\end{tabular}

a $\Uparrow$ : increase or induction; $\Downarrow$ : decrease or repression; ND: not determined. 


\section{Figure legends}

Figure 1: $\mathrm{NH}_{4}{ }^{+}$exposure impairs axonal growth during development, but does not affect axons after synaptogenesis. Immunohistochemistry against phosphorylated NFM. Day in vitro (DIV) 13 (A,B; development) or 28 (C,D; post-synaptogenesis) brain mixed-cell 3D cultures. A,C: control cultures; $\mathbf{B}, \mathbf{D}$ : cultures exposed to $5 \mathrm{mM} \mathrm{NH}_{4} \mathrm{Cl}$ from DIV 5 to 13 (B) or 20 to 28 (D). Bar: $100 \mu \mathrm{m}$. Data taken, and figure modified, from [16].

Figure 2: Intracellular levels of creatine (Cr) and guanidinoacetate (GAA) in 3D brain cell cultures under continued exposure of $\mathrm{NH}_{4} \mathrm{Cl}$ and/or $\mathrm{Cr} . \mathrm{Cr}$ and GAA intracellular levels measured by tandem mass spectrometry; day in vitro (DIV) 13 control cultures, as well as cultures exposed from DIV 5 to 13 to $5 \mathrm{mM} \mathrm{NH}_{4} \mathrm{Cl}, 1 \mathrm{mM} \mathrm{Cr}$, or both, and harvested at DIV 13. Data taken, and figure modified, from [18].

Figure 3: Axonal protection under $\mathrm{NH}_{4}{ }^{+}$exposure depends on a glial-dependent soluble factor. Immunohistochemistry against phosphorylated NFM, as in [16]. Mixed-cell (A-C) or neuron-enriched (D-G) 3D cultures grown from days in vitro 5 to 13 as in [16], with $(\mathbf{B}, \mathbf{C}, \mathbf{E}, \mathbf{F})$ or without $(\mathbf{A}, \mathbf{D}) 5 \mathrm{mM} \mathrm{NH}{ }_{4} \mathrm{Cl}$, and with $(\mathbf{G})$ or without (A-F) addition of medium from mixed-cell 3D cultures conditioned by $1 \mathrm{mM}$ Cr. Bar: $100 \mu \mathrm{m}$. 


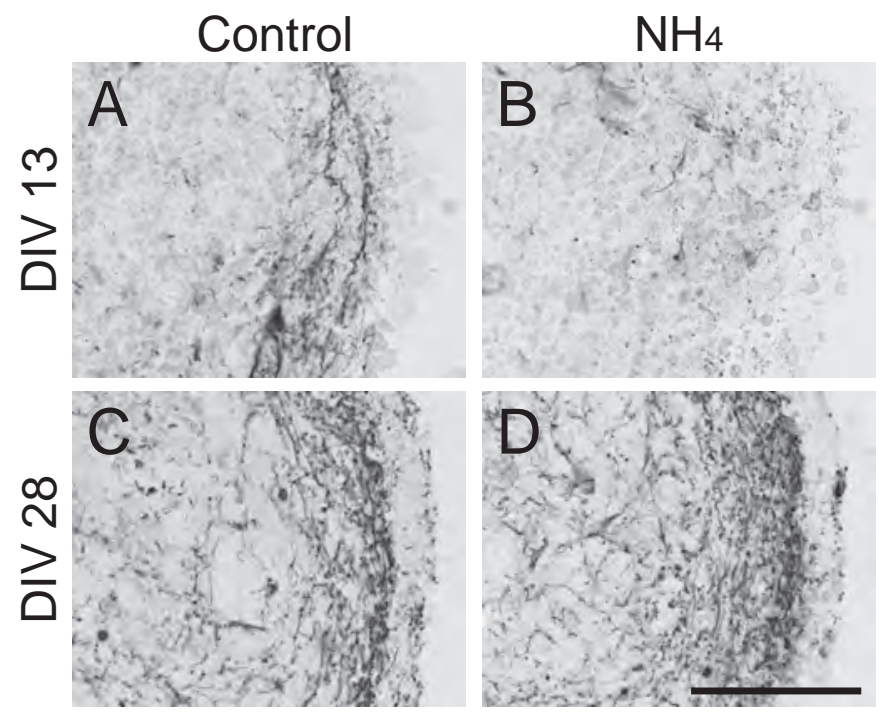




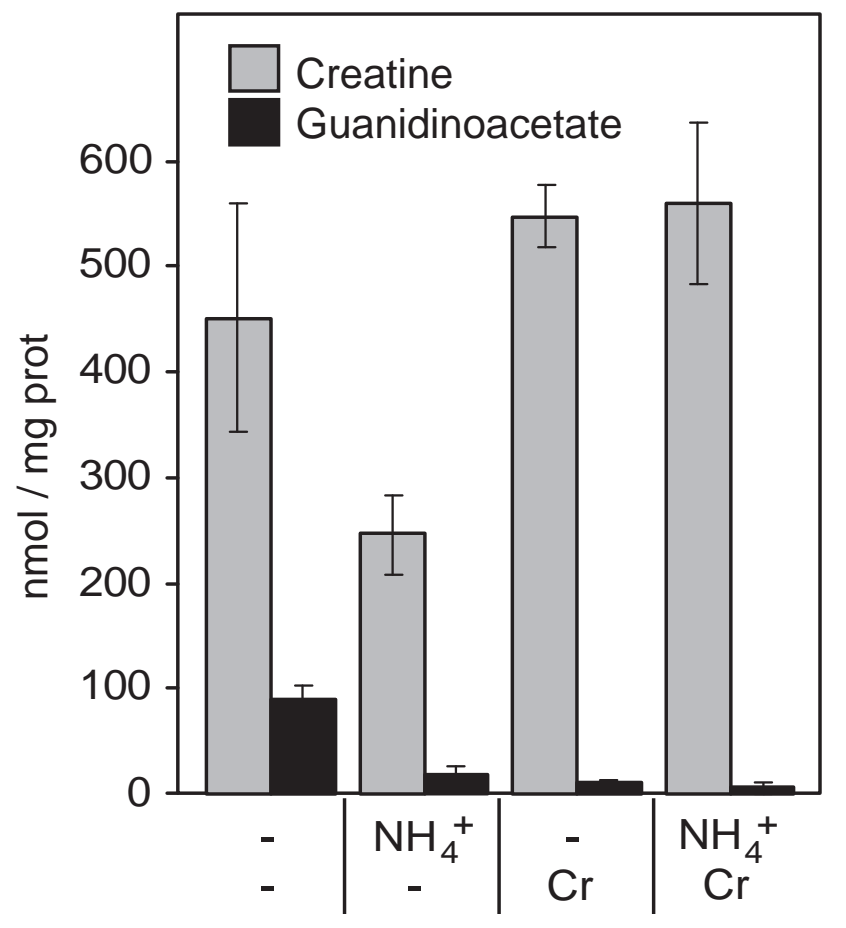




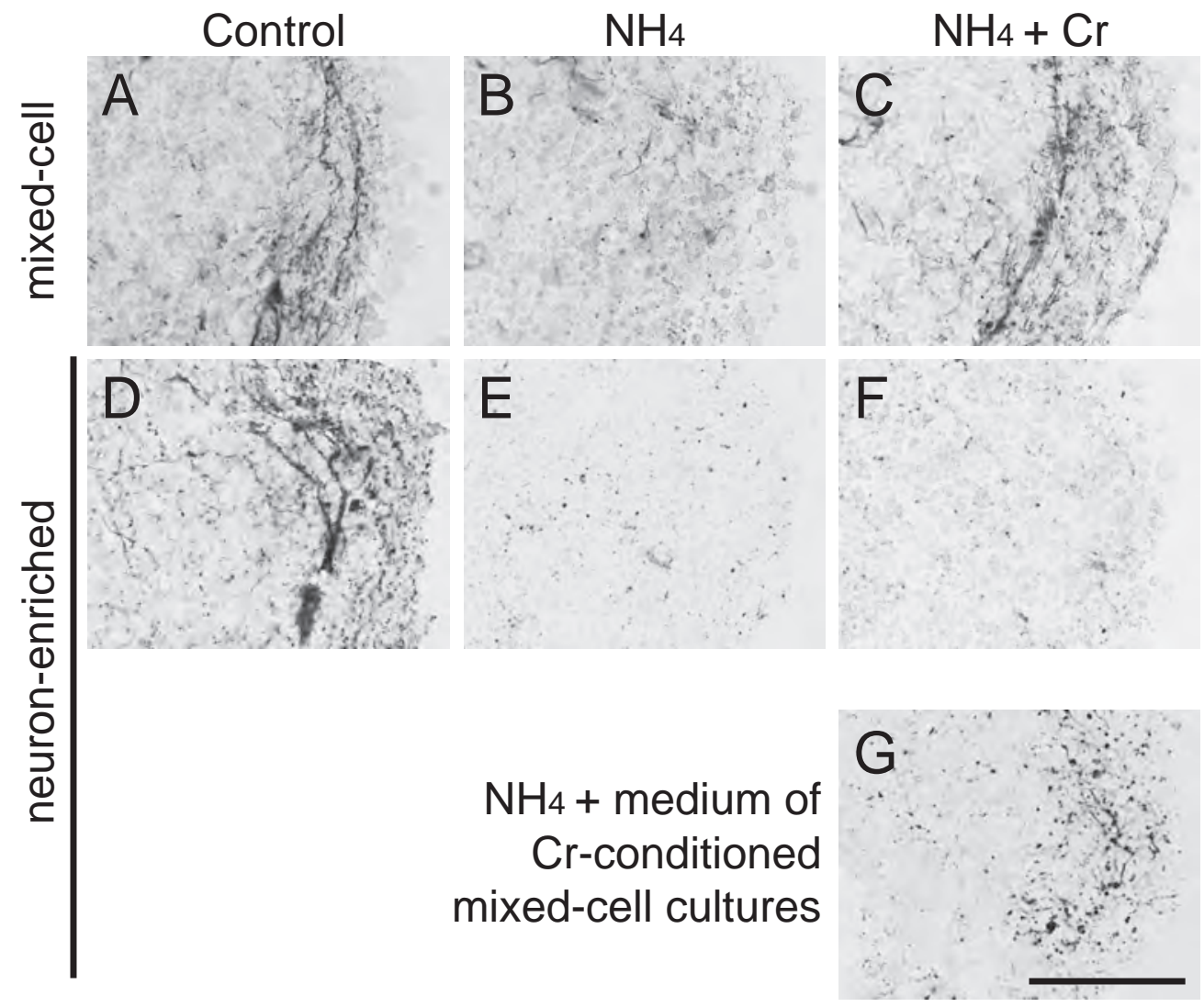

